\title{
OUTCOME OF DORSAL ONLAY URETHROPLASTY FOR LONG SEGMENT ANTERIOR URETHRAL STRICTURE: EXPERIENCE OF 31 CASES
}

\author{
HAFIZ AL-ASAD ${ }^{1}$, PRODYUT KUMAR SAHA ${ }^{1}$, A. K. M. SHAHADAT HOSSAIN¹, MD. WALIUL ISLAM ${ }^{2}$, AKM \\ MUSA BHUIYAN ${ }^{1}$
}

${ }^{1}$ Department of Urology, Dhaka Medical College \& Hospital, Dhaka, ${ }^{2}$ Department of Urology, National Institute of Kidney Diseases \& Urology, Dhaka

\begin{abstract}
:
Objective: To determine the short-term outcome of dorsolateral onlay urethroplasty in the treatment of long segment anterior urethral stricture.

Materials and Methods: A prospective study from May 2011 to September 2012 is carried out in department of Urology, National Institute of Kidney Diseases and Urology, Sher-EBanglanagar, Dhaka. Thirty one patients with long anterior urethral stricture were treated by a dorsolateral onlay buccal mucosa graft. After voiding trial, they were followed up at 3 weeks and 3 months with history, physical examination, uroflowmetry and retrograde urethrogram $(R G U)$ if required (uroflowmetry $<15 \mathrm{ml} / \mathrm{sec}$ ). Patients were further followedup at 3 months interval with uroflowmetry and retrograde urethrogram (RGU) if required (uroflowmetry $<15 \mathrm{ml} / \mathrm{sec}$ ). Successful outcome was defined as normal voiding with no surgical intervention after catheter removal.
\end{abstract}

Results: Mean stricture length was 42.49 $\pm 12.77 \mathrm{~mm}$ (range 24-70 mm) and mean follow up was 8 months (range 6 to 12 months). Three patients were found to develop stricture at anastomotic site, during follow-up and required optical internal urethrotomy and was considered as failure. One patient developed wound infection which resolved after regular dressing. Success rate was $90.32 \%$.

Conclusion: Dorsolateral onlay BMG urethroplasty is feasible for long anterior urethral stricture with good short term surgical outcome.

Key words: Urethral stricture, Buccal mucosal graft (BMG), Retrograde urethrogram (RGU), Voiding cystourethrogram (VCUG), Optical internal urethrotomy (OIU).

Bangladesh J. Urol. 2016; 19(1): 28-31

\section{Introduction:}

Urethral stricture is one of the oldest known urological diseases and remains a common problem with high morbidity. The urethral strictures are fibrotic narrowing composed of dense collagen and fibroblasts. Fibrosis usually extends into the surrounding corpus spongiosum, causing spongiofibrosis[1]. The treatment of urethral strictures varies according to location, length, depth and density of the stricture. Optical internal urethrotomy (OIU) may be useful for short annular strictures, but this procedure is associated to a very

Correspondence: Hafiz Al-Asad, Department of Urology, Dhaka Medical College \& Hospital, Dhaka, Email: hafizalasad34@ yahoo.com high recurrence rate[2]. Urethral reconstruction with excision of the strictured segment and end-to-end anastomosis is successful in more than $95 \%$ of patients with a stricture of up to $2 \mathrm{~cm}$ in length[3]. Patients with long strictures (> $2 \mathrm{~cm}$ in length) are not suitable for end-to-end urethroplasty due to the risk of postoperative chordee formation[4]. Substitution urethroplasty is ideal for the management of long anterior urethral strictures. The ideal material for substitution urethroplasty remains controversial[5]. Urethral substitution has long been accomplished by using genital skin flaps, grafts of genital or extragenital tissue[6]. Currently, buccal mucosa graft substitution urethroplasty is the most preferred option for long bulbar urethral strictures. Buccal mucosa offers 
the advantages of being accustomed to a wet environment, having good vascularity, hair less, easy to harvest, thick epithelium making it easy to handle and less chance of graft contracture, having a thin lamina propria allowing early inosculation, reduced rate of pseudo-diverticulum formation[6]. Weather to place the graft dorsally, ventrally or laterally is still controversial. Dorsal onlay graft procedure provides the advantages of better mechanical support by the corporal bodies with fewer incidences of sacculation and fistula formation but this approach may damage erectile function and the bulbar arteries when the dissection from the corpora needs to be very proximal[7]. As dorsal onlay urethroplasty requires circumferential mobilization of the urethra, this might cause ischemia of the urethra in addition to chordee. But in dorsolateral technique urethra was not separated from the corporal bodies on one side and was only mobilized from the midline on the ventral aspect to beyond the midline on the dorsal aspect. The urethra was opened in the dorsal midline over the stricture. The buccal mucosal graft was secured on the ventral tunica of the corporal bodies. In this study, we adopt this technique and tried to evaluate the short term outcome.

\section{Materials and Methods}

From May 2011 to September 2012, thirty one patients with long anterior urethral stricture were managed by single stage urethroplasty with a dorsolateral onlay patch BMG. Each patient was evaluated with history, physical examination, uroflowmetry, imaging study with retrograde urethrogram (RGU) and voiding cystourethrogram (VCUG) and other routine investigations required for anaesthetic fitness. All the patients were selected purposively according to the selection criteria that were, patients having primary and recurrent stricture of anterior urethra, stricture length more than $2 \mathrm{~cm}$, patients with significant lower urinary tract symptoms and patient given consent for operation and record for study purpose. Stricture involving posterior urethra and with oral pathology were excluded. Ethical committee's approval was taken to perform the study. Operation was performed under general anesthesia with naso-tracheal intubation and the patient was put in exaggerated lithotomy position. Operation was done in a 2-team approach-one team engaged in urethral procedure and other team in harvesting the buccal mucosa. Through a midline perineal incision, the bulbocavernosus muscle was divided exposing the corpus spongiosum of the anterior urethra. Then the anterior urethra was easily dissected from corpora cavernosa.
Then the strictured segment of the urethra was identified. The other team then harvested the buccal mucosal graft of adequate length, from the inner cheek area below the Stensen's duct without injuring it. Lignocaine (2\%) with adrenaline (1:200000) was injected into the edges of the desired graft length before harvesting to get better hemostasis. Graft donor site is closed with continuous 4-0 chromic catgut sutures to achieve good haemostasis. The graft was then defatted and tailored to its proper size. The dissected urethra was not separated from the corporal bodies on one side and was only mobilized from the midline on the ventral aspect to beyond the midline on the dorsal aspect. The urethra was opened in the dorsal midline over the stricture. The proximal and distal urethral lumens of the urethra were calibrated. The right margin of the graft was sutured with the urethral margin using 5-0 polyglactin suture. Foley catheter was inserted through the urethra into the urinary bladder. Then the left margin of the urethral mucosa was sutured to the graft using 5-0 polyglactin continuous suture. Few interrupted stitches were given to fix the buccal mucosal graft to secure on the ventral tunica of the corporal bodies. Suprapubic catheterization was done in all patients. The patient was maintained on antibiotics until the catheter was removed. Three weeks after the operation the urethral catheter was removed if patient could void well then the suprapubic catheter was removed on the next day. All the patients were advised to visit at outpatient door on 3 weeks and on 3 months for follow up. During follow up patient's history, physical examination, uroflowmetry were done. If uroflowmetry showed significant obstruction $(<15 \mathrm{ml} / \mathrm{sec})$ then retrograde urethrogram (RGU) and voiding cystourethrogram (VCUG) was done. A successful outcome was defined as normal voiding with no need of any kind of surgical inervention. Patients were further followed-up at 3 months interval with uroflowmetry and $R G U$ and VCUG if required (uroflowmetry $<15 \mathrm{ml} / \mathrm{sec}$ ). The results were calculated by SPSS- 13 .

\section{Results}

Total 31 patients, mean age $36.55 \pm 8.36$ years (range 21-53 years) were underwent BMG urethroplasty by dorsolateral onlay graft from May 2011 to September 2012. Most of the patients presented with poor flow of urine, some presented with per-urethral discharge and few of them presented with acute retention of urine. Cause of stricture was inflammatory $61.29 \%$, idiopathic $25.81 \%$, traumatic $6.45 \%$ and iatrogenic $6.45 \%$. Highest number of strictures 14 (45.16\%) were located in the bulbar part, penile urethral strictures were 10 (32.26\%) 
and $07(22.58 \%)$ strictures involved both bulbar and penile part. Mean stricture length was $42.49 \pm 12.77 \mathrm{~mm}$ (range $24-70 \mathrm{~mm}$ ). Before surgery mean peak urinary flow rate was $6.68 \pm 1.35 \mathrm{ml} / \mathrm{sec}$. Mean operative time was 110 min (range 100 to $160 \mathrm{~min}$ ) and mean follow-up was 8 months (range 6-12 months). All patients required peroperative blood transfusion but no patients required it postoperatively. Thirty patients were discharged on $4^{\text {th }}$ post-operative day, only one patient how developed wound infection was managed successfully with change in antibiotics as per wound swab culture sensitivity test and regular dressing and was discharged on $14^{\text {th }}$ postoperative. On urethral catheter removal of that patient, he could void well and needed no intervention. On follow up peak urinary flow rate improved significantly. At 3 weeks and at 3 months the mean peak urinary flow rate was $20.00 \pm 3.20$ and $20.19 \pm 3.45 \mathrm{ml} / \mathrm{sec}$ respectively. Two patients developed stricture at proximal anastomotic site which was addressed during follow up and required optical internal urethrotomy and was considered as failure. In our series the mean follow up was 8 months (range 6 to 12 months). In this study the success rate was $90.32 \%$ (28 patients) and failure rate was $9.68 \%$ (3 patients).

Table-I

Outcomes of dorsolateral onlay BMG urethroplast

\begin{tabular}{lc}
\hline Outcomes & Dorsolateral BMG urethroplasty \\
\hline Mean age of patients & $36.55 \pm 8.36$ years \\
Mean length of stricture & $42.49 \pm 12.77$ years \\
Mean peak urinary flow rate & $20.52 \pm 4.38$ years \\
at follow up & \\
Urinary tract infection & $9.68 \%$ \\
Wound infection & $00 \%$ \\
Urethrocutecous fistula & $00 \%$ \\
Recurrence of stricture & $9.68 \%$ \\
Overall success & $90.32 \%$ \\
\hline
\end{tabular}

\section{Discussion}

Urethral strictures were documented in ancient literature dating from Greek and Egyptian period. Continuous attempts are made in different parts of the world in different centers to find out an ideal method of treatment according to the merit of individual type of stricture. Significant progress made over the last 30 years[8]. A circumferential dissection of the whole anterior urethra risks the vascularity of the urethra, which may be more important if the meatus is involved with disease and the distal-most urethra is extensively dissected, such as is seen with concomitant lichen sclerosis. The Barbagli procedure with circumferential mobilization of the urethra for dorsal onlay patch has a success rate of $99 \%$ in the short-term[9]. However, in long segment anterior urethral strictures, circumferential urethral mobilization may jeopardize the lateral vascularity of the urethra. Barbagli also described the lateral onlay procedure with results similar to dorsal and ventral onlay for bulbar urethral strictures[10]. Asopa's procedure of inlay patch by ventrally incising the urethra is another option for anterior urethral strictures[11]. It preserves the lateral vascularity of the urethra. However, it has two potential drawbacks. Firstly, a wider graft may be difficult to be placed using this approach and may likely get folded. Secondly, we do not know how the long ventral saggital incision on the scarred urethra will behave in the long-term followup. In the short-term follow-up, this procedure has shown good results[11,12]. To maintain the urethral vascularity on one side of the urethra while keeping the graft in a dorsolateral onlay fashion, we adopted the policy of limited urethral mobilization, i.e., from ventral midline to beyond dorsal midline. In this procedure, the vascular supply of the urethra of the other side is maintained. We kept the grafts of up to $20 \mathrm{~mm}$ in width with a maximum length from 24 to $70 \mathrm{~mm}$. Technically, it is as easy as the Barbagli procedure. It also preserves the one-sided bulbar artery in addition to maintaining the native lateral vascularity at the distal urethra. Furthermore, by using this approach, we did not find postoperative chordee in any case. In this procedure, the urethra is not completely mobilized off the corpora; hence, graft sizing is more appropriate, preventing the chordee. We cannot comment on postoperative sexual and ejaculatory function as we specifically did not look into this matter. Muscle and nerve sparing onlay patch urethroplasty have been suggested for better ejaculatory function and to avoid post void dribbling[13]. None of our patients reported post void dribbling. The success rate of our study is similar to other studies[9,13]. In our series short-term results for the long segment anterior urethral strictures are reasonable.

\section{Conclusion}

Dorsal onlay urethroplasty for long segment anterior urethral structure is an effective procedure with minimal post operative complication. The success rate is $90.32 \%$. So we recommend this produre for long segment anterior urethral stricture. 


\section{References}

1. McAninch, J.W. Disorders of the penis and male urethra. In: Tanagho, E.A., McAninch, J.W., eds. Smith's general urology. $17^{\text {th }}$ ed. West Patel Nagar, New Delhi: Tata McGraw-Hill Co. 2009; 625637.

2. Heyns C.F, Steenkamp J.W, DeKock M.L, Whitaker P. Treatment of male urethral strictures: is repeateddilation or internal urethrotomy useful? . J Urol. 1998; 160: 356-8.

3. Webster G.D, Robertson C.N. The vascularized skinisland urethroplasty: its role and results in urethralstricture management. J Urol. 1985; 133: 31-3.

4. Gupta N.P, Ansari M.S, Dogra P.N, Tandon S. Dorsal buccal mucosal graft urethroplasty by a ventral sagittal urethrotomy and minimal-access perineal approach for anterior urethral stricture. BJU Int. 2004; 93: 1287-90.

5. Bhargava S., Chapple C.R. Buccal mucosalurethroplasty: is it the new gold standard? BJU Int. 2004; 93: 1191-3.

6. Morey A.F. \& McAninch J.W. Techniques of harvesting buccal mucosa for urethral reconstruction. J Urol. 1996; 155: 1696.

7. Iselin C.E \& Webster G.D. Dorsal onlay graft urethroplasty for repair of bulbar urethral strictures. J Urol. 1999; 161: 815-18.

8. Jordan G.H. and Schlossberg S.M. Surgery of the penis and urethra. In: Wein, A.J., Kavoussi, L.R.,
Novick, A.C., Partin, A.W., Peter, C.A., eds. Campbell's Urology. $9^{\text {th }}$ ed. Philadelphia: Saunders. 2007; 1023-1097.

9. Barbagli G., Morgia G., Lazzeri M. Dorsal onlay skin graft bulbar urethroplasty: Long-term followup. Eur Urol. 2008; 53: 628-33.

10. Barbagli G., Palminteri E., Guazzoni G., Montorsi F., Turini D., Lazzeri M. Bulbar urethroplasty using buccal mucosa grafts placed on the ventral, dorsal or lateral surface of the urethra: Are results affected by the surgical technique? J Urol. 2005; 174: 955-7.

11. Asopa H.S, Garg M., Singhal G.G., Singh L., Asopa J., Nischal A. Dorsal free graft urethroplasty for urethral stricture by ventral sagittal urethrotomy approach. Urology. 2001; 58:657-9.

12. Pisapati V.L., Paturi S., Bethu S., Jada S., Chilumu R., Devraj R., et al. Dorsal buccal mucosal graft urethroplasty for anterior urethral stricture by asopa technique. Eur Urol. 2008. Jun 9. 2008 Jun 9. [Epub ahead of print]

13. Barbagli G., De Stefani S., Annino F., De Carne C., Bianchi G. Muscle and nerve-sparing bulbar urethroplasty: A new technique. Eur Urol. 2008;.54:335-43.

Abbreviations:

BMG : Buccal mucosal graft

OIU : Optical Internal Urethrotomy

RGU : Retrograde Urethrogram

VCUG : Voiding Cystourethrogram 